\title{
Study on Wind-Induced Fatigue of UHV Transmission Tower-Line Coupled System in Hilly Terrain Wind Field
}

\author{
Chuntao Zhang and Junjie Wang \\ School of Civil Engineering and Architecture, Southwest University of Science and Technology, Mianyang, 621010, China
}

\begin{abstract}
Given the characteristics of hilly terrain wind field is radically distinct from flat terrain wind field due to the interference of hills, the existing calculation methods of flat terrain wind field cannot be adopted directly to conduct a study on the wind-induced response of ultra-high voltage (UHV) transmission tower with higher structure and larger span. In this paper, the effect of two types of mountainous terrains, which include eight different gradients and three different heights, is studied based on a wind tunnel test. The relevant modified formula of topographic effect is proposed considering the variance of mean speed ratio of wind speed and turbulence intensity, and the characteristics of average wind and fluctuating wind are obtained. Based on the proposed wind-field model and test data, a dynamic history analysis of UHV transmission towerline coupled system is conducted by utilizing finite element theory Meanwhile, a wind-induced fatigue computational method of UHV transmission tower is proposed combining with the joint distribution model and the linear fatigue cumulative damage rule.
\end{abstract}

Keywords-hilly terrain wind field; UHV transmission tower; wind-induced fatigue; Speed-up ratio; turbulence intensity

\section{INTRODUCTION}

UHV transmission tower-line coupled system, which possesses the characteristics of high tower structure and large span, is prone to collapse due to its sensitivity to wind load response. For a long time, the research on wind-induced fatigue of transmission tower system has drawn extensive attention from scholars. Crandall and Winsterstein ${ }^{[5-6]}$ conducted researches on fatigue cumulative damage of narrow band Gaussian process and non Gaussian process respectively, and Wirsching ${ }^{[7]}$ proposed an equivalent narrow band method based on the concept of equivalent stress amplitude. Holmes ${ }^{[8]}$ proposed a simplified method to estimate the range of windinduced fatigue damage in towering structures considering the average wind speed and distribution of wind angles. Deng et al. [9] utilized equivalent stress method, rain-flow method and equivalent narrow band method to conduct a wind-induced fatigue research on lattice mast structure. Wang et al. [2] conducted a wind-induced fatigue research on transmission tower-line coupled system by using time domain analysis method, and residual life of transmission tower under the wind vibration effect was estimated efficiently. However, UHV transmission towers are in the wind field affected by mountainous terrain during the entire service period in practical engineering. Thus, a wind-induced fatigue computational method of UHV transmission tower is proposed based on linear fatigue damage theory and test data available, and the windinduced fatigue of UHV is analyzed.

\section{WIND TUNNEL TEST}

\section{A. Overview}

The test was conducted in the FL-11 wind tunnel at the low speed center of China aerodynamics research and development center, and the section size of the wind tunnel is $1.4 \mathrm{~m} \times 1.4 \mathrm{~m}$, the length of the test section is $6.3 \mathrm{~m}$. The experimental geometric model scale ratio is $1: 1000$,and the wind speed scale ratio is $1: 2.5$. The frequency of sampling is $156 \mathrm{~Hz}$. The time step of each measuring point is 4096, and the height of the calandria is $0.7 \mathrm{~m}$. The distribution of probes was illustrated in Fig.1.

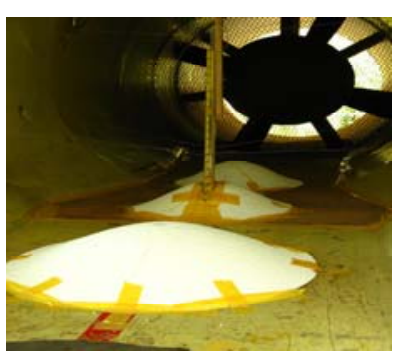

FIGURE I. THE WIND TUNNEL TEST OF HILLY TERRAIN WIND FIELD

The cosine square type mountain model is selected in the test, and the expression is given as:

$$
z=h \cos ^{2}(\pi r / 4 L)
$$

The expression of $r$ varies in different mountain models, where $\mathrm{r}$ is equivalent to horizontal coordinates $\mathrm{x}$ in twodimensional mountain model. While in three-dimensional mountain model, $r$ is equal to $\sqrt{x^{2}+C^{2} y^{2}}$, where $C$ is a shape constant. The mountain height is $h$, and $L$ represents the horizontal distance from the summit to half the height of the mountain.

The test conditions of two types of mountain terrain are illustrated respectively as follows: (1)S1 S8 represent the variation of single mountain slope, which are $1.00,0.75,0.60$, $0.50,0.43,0.38,0.33$ and 0.30 . (2) H1 H3 represent the 
variation of single mountain height, which are $100 \mathrm{~mm}, 150 \mathrm{~mm}$ and $200 \mathrm{~mm}$. The average wind speed of each test condition is $15 \mathrm{~m} / \mathrm{s}$, and the wind speed time history of wind profiles, which include five critical positions in along-wind ridge and 5 classic position in downwind area, are collected.

\section{B. Test results analysis}

- Test results of the variation of mountain slope

The average wind speed in a mountainous terrain has increased compared with the average wind speed at the height of the ground, and the increment is significant near the top of the mountain. Therefore, speed-up ratio is used as a dimensionless parameter to quantitatively describe this acceleration effect in the mountain wind field. The expression is given as:

$$
\Delta S=\frac{U(z)-U_{0}(z)}{U_{0}(z)}
$$

Where $U(z)$ is the wind speed at the height of $\mathrm{z}$ above the ground of mountain, $U(z)$ is the wind speed at the height of $z$ above the flat ground.
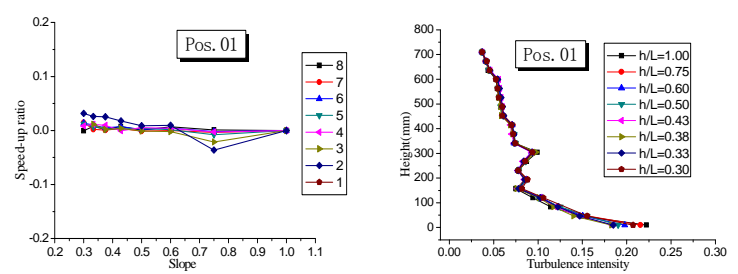

(a) Windward side
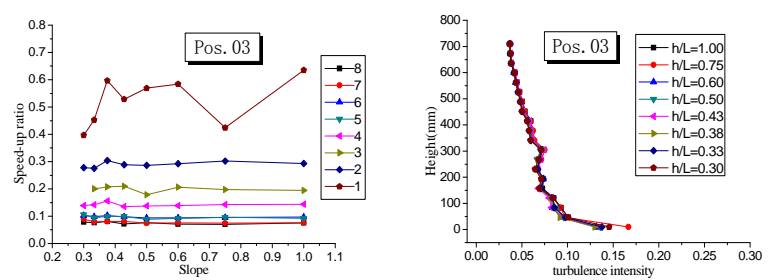

(b) Mountaintop
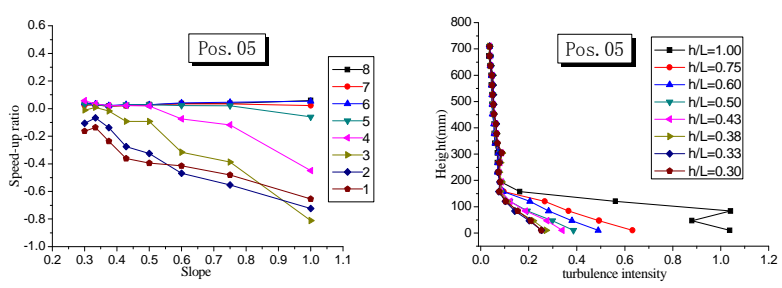

(c) Leeward side

FIGURE II. EFFECT OF SLOPE ON WIND FIELD

The results of the test on the impact of different mountain slopes towards the wind field are shown in Fig. 2. Figure4(a) shows that the slope has no effect on the turbulence of the windward slope and its spatial distribution, whereas the average wind speed at the summit is higher than that at the leeward side and windward side; Figure2(b) shows that the average wind speed-up ratio of the lowest measuring point increased slightly with the increment of slope; Figure2(c) shows that the average wind speed-up ratio of the measuring points on the leeward surface varied greatly. Meanwhile, it can be noted that the flow separation was produced on the leeward side as the slope increases, and a vortex was formed with a center wind speed of 0 eventually.

- Test results of the variation of mountain height

With the same slope and different mountain height, the maximum wind speed-up ratio at the windward side, leeward side and the summit of mountain are shown in Table 1. It could be noted from the analysis that the maximum mountain surface speed-up ratio of windward side is relatively small, and the characteristics of average wind in the wind field remain unchanged; The speed-up ratio at the summit of the mountain increased with the increase of the height, and the speed-up ratio of the ground significantly improved. Meanwhile, the turbulence intensity of three test conditions are derived in Fig.3. Turbulence increased with the decrease of height away from the ground.

TABLE I. EFFECT OF HILL HEIGHT ON MAXIMUM SPEED-UP RATIO

\begin{tabular}{|c|c|c|c|c|c|c|c|c|c|}
\hline \multirow{2}{*}{ Height/mm } & \multicolumn{3}{|c|}{ Windward side } & \multicolumn{3}{|c|}{ Mountaintop } & \multicolumn{3}{|c|}{ Leeward side } \\
\hline & $100 \mathrm{~mm}$ & $150 \mathrm{~mm}$ & $200 \mathrm{~mm}$ & $100 \mathrm{~mm}$ & $150 \mathrm{~mm}$ & $200 \mathrm{~mm}$ & $100 \mathrm{~mm}$ & $150 \mathrm{~mm}$ & $200 \mathrm{~mm}$ \\
\hline 10 & 0.0387 & 0.0421 & 0.04633 & 0.4110 & 0.5692 & 0.6344 & -0.4195 & -0.3944 & -0.2970 \\
\hline 47 & 0.0286 & 0.0310 & 0.0347 & 0.2634 & 0.2862 & 0.3173 & -0.0756 & -0.3247 & -0.3257 \\
\hline 121 & 0.0119 & 0.0126 & 0.0186 & 0.1199 & 0.1376 & 0.1606 & 0.0386 & 0.0195 & -0.0912 \\
\hline 158 & 0.0078 & 0.0093 & 0.0137 & 0.0818 & 0.0883 & 0.1057 & 0.0379 & 0.0283 & 0 \\
\hline 195 & 0.0052 & 0.0075 & 0.0086 & 0.0837 & 0.0935 & 0.1106 & 0.0374 & 0.0278 & 0.0222 \\
\hline
\end{tabular}




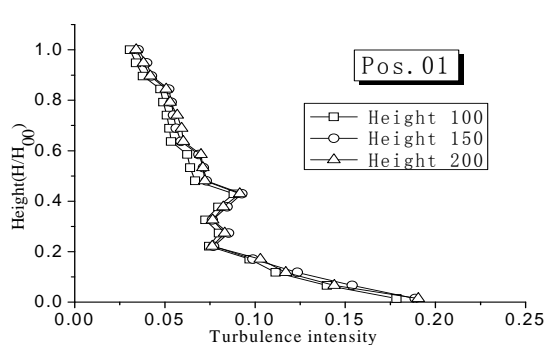

(a) Windward side

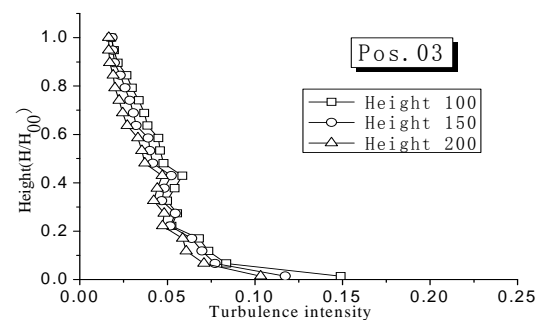

(b) Mountaintop

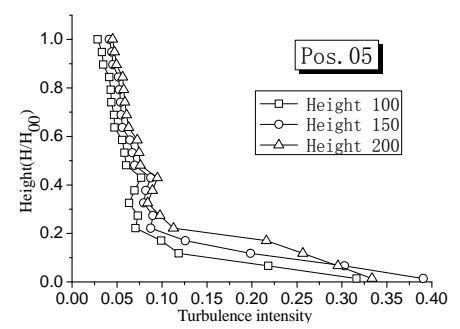

(c) Leeward side

FIGURE III. EFFECT OF HEIGHT ON WIND FIELD

The impact of mountain heights on the average wind speedup ratio at the summit and leeward side can be considered in the study of mountain wind field in which the height correction factor can be considered.

The summit of the mountain:

$$
\eta_{h B}=-1.75+10.9 h / H_{G}-10.4\left(h / H_{G}\right)^{2}
$$

Leeward side:

$$
\eta_{h B}=2.53-5.15 h / H_{G}+3.7\left(h / H_{G}\right)^{2}
$$

Meanwhile, the impact on mountain heights on fluctuating wind can be considered as:

$$
\eta_{\sigma h}=1.17-4.35 h / H_{G}+6.61\left(h / H_{G}\right)^{2}
$$

Where $h$ is the height of a mountain and $H_{G}$ is the gradientwind level.

\section{WIND-INDUCED FATIGUE CALCULATION OF UHV TRANSMISSION TOWER-LINE SYSTEM}

\section{A. Calculation Method of Wind-Induce Fatigue}

The wavelet analysis is adopted to simulate the corresponding wind field, then the time-history analysis of UHV transmission tower-line system on various wind fields is conducted. Thus, the stress time history [ $\left.\sigma_{i, j}\right]$ of key members in transmission tower-line system under different wind speeds in all directions can be obtained(wind direction $i=1,2, \ldots, 16$ and wind speed $j=1,2, \ldots, 26)$. The mean value of stress in the calculation varies with wind speed. Therefore, fatigue analysis should be corrected by Goodman model to obtain the equivalent stress amplitude matrix, given as:

$$
[\Delta \sigma]=\left[\begin{array}{cccc}
\left\{\Delta \sigma_{1,1}\right\} & \left\{\Delta \sigma_{1,2}\right\} & \cdots & \left\{\Delta \sigma_{1,26}\right\} \\
\left\{\Delta \sigma_{2,1}\right\} & \left\{\Delta \sigma_{2,2}\right\} & \cdots & \left\{\Delta \sigma_{2,26}\right\} \\
\vdots & \vdots & \cdots & \vdots \\
\left\{\Delta \sigma_{16,1}\right\} & \left\{\Delta \sigma_{16,2}\right\} & \cdots & \left\{\Delta \sigma_{16,26}\right\}
\end{array}\right]
$$

Obviously, substituting (6) into the following formula as:

$$
\lg \sigma=A+B \lg N
$$

The fatigue life of the transmission tower under different wind speeds can be derived as:

$$
\left[\begin{array}{cccc}
\lg \left\{\Delta \sigma_{1,1}\right\} & \lg \left\{\Delta \sigma_{1,2}\right\} & \cdots & \lg \left\{\Delta \sigma_{1,26}\right\} \\
\lg \left\{\Delta \sigma_{2,1}\right\} & \lg \left\{\Delta \sigma_{2,2}\right\} & \cdots & \lg \left\{\Delta \sigma_{2,26}\right\} \\
\vdots & \vdots & \cdots & \vdots \\
\lg \left\{\Delta \sigma_{16,1}\right\} & \lg \left\{\Delta \sigma_{16,2}\right\} & \cdots & \lg \left\{\Delta \sigma_{16,26}\right\}
\end{array}\right]=A+B \lg \left[N_{i, j}\right]
$$

Where $A=l g C / m$ and $B=-1 / m . C$ and $m$ are parameters relating to materials, stresses and loading methods, etc. And the fatigue life matrix of transmission tower with different wind speed in different wind direction can be obtained by (8), given as:

$$
\left[N_{i, j}\right]=\left[\begin{array}{cccc}
\left\{N_{1,1}\right\} & \left\{N_{1,2}\right\} & \cdots & \left\{N_{1,26}\right\} \\
\left\{N_{2,1}\right\} & \left\{N_{2,2}\right\} & \cdots & \left\{N_{2,26}\right\} \\
\vdots & \vdots & \cdots & \vdots \\
\left\{N_{16,1}\right\} & \left\{N_{16,2}\right\} & \cdots & \left\{N_{16,26}\right\}
\end{array}\right]
$$

Meanwhile, the number of transmission tower cycle corresponding to the equivalent stress amplitude can be obtained throughout the statistical analysis: 


$$
\left[n_{i, j}\right]=\left[\begin{array}{cccc}
\left\{n_{1,1}\right\} & \left\{n_{1,2}\right\} & \cdots & \left\{n_{1,26}\right\} \\
\left\{n_{2,1}\right\} & \left\{n_{2,2}\right\} & \cdots & \left\{n_{2,26}\right\} \\
\vdots & \vdots & \cdots & \vdots \\
\left\{n_{16,1}\right\} & \left\{n_{16,2}\right\} & \cdots & \left\{n_{16,26}\right\}
\end{array}\right]
$$

According to Miner cumulative damage theory, which is:

$$
D_{i, j}=\frac{n_{i, j}}{N_{i, j}}
$$

The damage matrix of bars under different wind directions and wind speed is derived as:

$$
\left[D_{i, j}\right]=\left[\begin{array}{cccc}
D_{1,1} & D_{1,2} & \cdots & D_{1,26} \\
D_{2,1} & D_{2,2} & \cdots & D_{2,26} \\
\vdots & \vdots & \cdots & \vdots \\
D_{16,1} & D_{16,2} & \cdots & D_{16,26}
\end{array}\right]
$$

Then, according to the wind speed and wind direction data, the joint distribution probability of different wind speeds in each wind direction can be calculated as:

$$
\left[P_{i, j}\right]=\left[\begin{array}{cccc}
P_{1,1} & P_{1,2} & \cdots & P_{1,26} \\
P_{2,1} & P_{2,2} & \cdots & P_{2,26} \\
\vdots & \vdots & \cdots & \vdots \\
P_{16,1} & P_{16,2} & \cdots & P_{16,26}
\end{array}\right]
$$

Therefore, the damage of transmission tower in the whole calculation period $T$ is derived combining with (12) and (13), given as:

$$
\left[D_{i, j}\right]_{T}=\left[\begin{array}{cccc}
P_{1,1} D_{1,1} & P_{1,2} D_{1,2} & \cdots & P_{1,26} D_{1,26} \\
P_{2,1} D_{2,1} & P_{2,2} D_{2,2} & \cdots & P_{2,26} D_{2,26} \\
\vdots & \vdots & \cdots & \vdots \\
P_{16,1} D_{16,1} & P_{16,2} D_{16,2} & \cdots & P_{16,26} D_{16,26}
\end{array}\right]
$$

The total damage in $T$ time is obtained by adding each term in the upper right matrix:

$$
D_{T}=\sum_{i=1}^{16} \sum_{j=1}^{26} D_{i, j} P_{i, j}
$$

Based on the Miner cumulative damage theory, the ultimate fatigue life of transmission tower can be obtained as:

$$
T_{L}=\frac{T}{D_{T}}
$$

As mentioned above, the fatigue life of the key members in the transmission tower can be calculated and the fatigue life can be predicted.

\section{B. Analysis of Calculation Results}

Based on engineering examples and wind tunnel tests [1-3], the total height of the UHV long-span transmission tower is employed as $108 \mathrm{~m}$, the design strength of the rod is employed as $345 \mathrm{MPa}$, the fatigue parameter of the component material is employed as $C=0.41 \times 1012$ and $\beta=3$, and the service period is employed as 100 years. The finite element model is shown in Fig.4.

The fatigue life span of the most unfavorable members of tower-line system at windward side, summit and leeward side under different operating conditions is calculated by using the method of wind-induced fatigue given in Section 2.1.Hence, the fatigue life span of the transmission tower-line system is derived, as shown in Table 2.

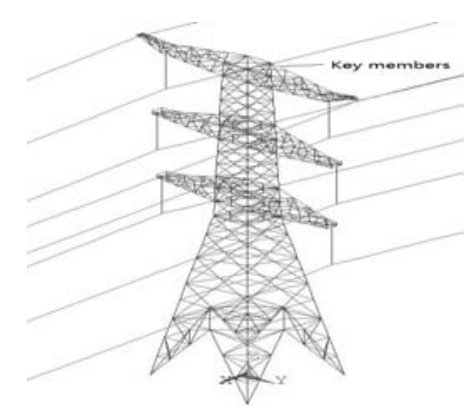

FIGURE IV. THE DIAGRAM OF MODEL SEGMENTS

TABLE II. FATIGUE LIFE OF KEY MEMBERS UNDER DIFFERENT HILLY TERRAIN WIND FIELD(YEAR)

\begin{tabular}{ccccccc}
\hline \multirow{2}{*}{ Terrain } & Test & \multicolumn{2}{c}{ Windward side } & Mountaintop & \multicolumn{2}{c}{ Leeward side } \\
& con. & Pos.01 & Pos.02 & Pos.03 & Pos.05 & Pos.10 \\
\hline mountain & 0.3 & 148 & 152 & 145 & 136 & 148 \\
slope & 0.5 & 138 & 141 & 133 & 133 & 146 \\
& 1.0 & 120 & 133 & 124 & 126 & 147 \\
mountain & 100 & 151 & 151 & 122 & 127 & 151 \\
height & 150 & 132 & 124 & 125 & 119 & 148 \\
\hline
\end{tabular}

It is obvious that the fatigue life of transmission tower decreases with the increase of slope and height of the mountain, and the fatigue life of the tower at the foot of the leeward side decreases gradually with the increase of the distance of the downwind direction. Thus, the life span increases accordingly.

To sum up the above, the wind field at the foot of the leeward surface is greatly affected by the mountain topography in the two types of mountainous terrain. The pulsation characteristic is remarkable and lead to a significant damage towards transmission tower. 


\section{CONCLUSION}

(1)The slope of a mountain has limited effect on the average wind and pulsating wind on the upwind surface and the summit of the mountain. However, although the height of the mountain has limited effect on the average wind on the upwind surface and on the top of the mountain, the pulsating wind on the near earth varies with the increase of the height of the mountain; Both of slope and height exert significant impact on the average wind and fluctuating wind of the leeward surface.

(2)In the two types of mountain terrain, the wind field at the foot of the mountain of the leeward side is most affected by the mountain topography, and the fatigue life of the transmission tower is the least, whereas the fatigue life increases with the increase of the downwind distance; The change of transmission tower fatigue life span of windward side and the summit of the mountain is limited.

\section{ACKNOWLEDGMENT}

The author would like to acknowledge the support by the National Natural Science Foundation of China(No.51508482).

\section{REFERENCES}

[1] Xiao Zhengzhi. Wind-induced response analysis and equivalent wind loads of UHV transmission tower [D]. Doctoral Thesis of Chongqing University, 2009, 5 ( in Chinese)

[2] Wang Zhisong. Study on wind-induced response and fatigue of UHV transmission tower-line coupled system [D]. Doctoral Thesis of Chongqing University, 2009, 9 ( in Chinese)

[3] Li Zhengliang, Xiao Zhengzhi, Han Feng, et al. Aeroelastic model design and wind tunnel tests of $1000 \mathrm{kV}$ Hanjiang long span transmission line system [J]. Power System Technology,2008, 32(12): 1-5 (in Chinese)

[4] Wang Zhisong, Li Zhengliang, Xiao Zhengzhi et al.. Equivalent AlongWind Direction Static Wind Load of Transmission Tower for $1000 \mathrm{kV}$ Double Circuit Transmission Lines on Same Tower[J]. Power System Technology, 2009, 33(14): 6-12 (in Chinese)

[5] Crandall S H, Mark W D. Rand vibration in mechanical systems [M]. New York: Academic press, 1963.

[6] Winterstein S R. No-linear vibration models for extremes and fatigue [J]. Journal of engineering mechanics, ASCE, 1986,114: 1772-1790.

[7] Wirsching P H. Fatigue under wide band random stresses [J]. Journal of the structural division, 1980, 106: 1593-1607.

[8] Holmes J D. Fatigue life under along-wind loading: closed-form solution [J]. Engineering structures, 2002, 24: 109-114.

[9] Deng Hongzhou, Wen Yinglong, He Pengfei. Analysis of fatigue reliability of the lattice Guyed-mast along wind vibration[J]. Special Structures, 2004, 21(2): 31-35 (in Chinese) 